SECTION 18. Culturology.

Jasper Waugh-Quasebarth researcher of National Museum of Natural History Smithsonian Institution, Washington, USA

Hasanov Elnur Latif oglu $\mathrm{Ph} . \mathrm{D}$. postgraduate correspondent member of International Academy of Theoretical \& Applied Sciences, scholar of Ganja Branch of Azerbaijan National Academy of Sciences,

Ganja, Azerbaijan

el-hasanov@mail.ru

\title{
TYPICAL ORNAMENTAL CHARACTERISTICS OF CERAMIC WARES OF GANJA FOR THE ANCIENT PERIOD
}

Abstract: On the basis of indisputable arguments and facts in offered article it was proved, that owing to development of the constructive-plastic forms, also decorativeornamental characteristics of ceramic patterns of Ganja of the early Iron Age epoch are considered the unique wares.

Key words: ceramics trade, period of an early Iron Age, Ganja, decorative-ornamental characteristics, Azerbaijan, constructive-plastic forms of pottery wares

\section{ХАРАКТЕРНЫЕ ОРНАМЕНТАЛЬНЫЕ ОСОБЕННОСТИ КЕРАМИЧЕСКИХ ИЗДЕЛИЙ ГЯНДЖИ АНТИЧНОГО ПЕРИОДА}

Аннотация: На основе неоспоримых аргументов и фактов в предлагаемой статье было доказано, что благодаря развитию конструктивно-пластических форм, а также декоративно-орнаментальных особенностей гончарных изделий Гянджи эпохи раннего железа, данные керамические образцы считаются уникальными изделиями.

Ключевые слова: гончарное ремесло, период раннего железного века, Гянджа, декоративно-орнаментальные особенности, Азербайджан, конструктивнопластические формы глиняных изделий

Еще с эпохи неолита, а также энеолита на территории древней Гянджи изготавливались ранние керамические изделия. Этот факт доказывают обнаруженные многочисленные образцы гончарного ремесла с территории Гянджи и ее окрестностях. Благодаря постепенному усовершенствованию ремесленных традиций керамики в период раннего железного века возникли основные характерные особенности гончарного ремесла этого древнего города. Так же, наблюдалось особое развитие в конструктивно-пластических формах художественной керамики. Нужно отметить что, основными характерными изделиями данного исторического периода древней Гянджи считаются белоинкрустированные керамические сосуды [1-3].

Характерные декоративно-орнаментальные особенности белоинкрустированной керамики отличаются разнообразностью. Очень важным элементом декоративноорнаментальных особенностей керамики Гянджи раннего железного века является художественное значение керамических форм [2-4]. 
Кроме того, характерной особенностью белоинкрустированной керамики Гянджи раннего железного века считается богатая и разнообразная орнаментация. В орнаменте данного исторического периода выделяются три основных элемента:

1. Антропоморфные элементы (изображения людей).

Данные элементы по манере исполнения имеют некоторые отличительные особенности как антропоморфные изображения, составленные из элементов геометрических фигур имеют полностью орнаментальный характер [5], изображения, составленные из волнистых линий отличаются точками, заполненными внутри орнамента и остальные антропоморфные изображения состоят из треугольников и передают человеческую фигуру достаточно реалистично и с рядом деталей [6].

2. Зооморфные элементы (изображения животных и птиц).

Эти изображения достаточно схематичные. Но по манере их можно разделить на следующие основные типы:

1) Наиболее реалистические изображения, исполненные при помощи двойных линий с четко выраженными элементами тела животного - ногами, головой.

2) Изображения, сделанные при помощи округлых линий и, как правило, заполненные точками [3-7];

3) Схематичные изображения животных, весьма приблизительно передающие контуры тела;

4) Полностью геометризированные изображения, в которых тело животного передается при помощи двух треугольников, составленных вершинами, а в основе тела птицы лежит треугольник.

Изображения людей и животных известны в крашеной керамике Передней Азии. На территории Ирана в историко-археологиических памятниках Бампур, Сузы I, Персеполь были обнаружены схожие орнаменты [11-14].

Нужно отметить что, человеческие изображения, составленные из треугольников, встречены среди геометрических орнаментов могильника Шахи-Тумп в Белуджистане [7].

3. Геометрический элемент.

Данный элемент состоит из заштрихованных треугольников, расположенных рядами и вписанных в другие, более сложные фигуры, а также ромбов и меандра.

В этот орнамент входят углы, свастика, кресты, косые штрихи, прямые полосы и т.п. С научной точки зрения огромный интерес вызывает тот факт, что существует разительное сходство между геометрической орнаментацией белоинкрустированной керамики Гянджи (и всего Восточного Закавказья) и нарезным орнаментом андроновской культуры [8].

Кроме того, среди геометрических элементов керамических изделий древней Гянджи данного периода значительно реже встречаются спираль, кружки и сложные фигуры, составленные не прямыми, а волнистыми линиями.

Все эти фигуры иногда существуют отдельно, чаще же соединяются в более или менее устойчивые сочетания. Наиболее частое сочетание-ромб, осложненный дополнительными треугольниками и углами [9].

Данный элемент, а также ряд похожих орнаментальных мотивов белоинкрустированной керамики древней Гянджи раннего железного века связывается с орнаментом крашеной керамики всего обширного переднеазиатского региона. Кроме того, виды художественного убранства керамических изделий также считаются основными ремесленными факторами керамики этого древнего города данной исторической эпохи. Главными видами художественного убранства глиняных сосудов являлись рельефнодекоративное убранство, врезная орнаментация и графический способ в декоративном убранстве [10-12]. 
Важными историко-этнографическими показателями развития гончарного ремесла в древней Гяндже, а также на территории долины реки Гянджачай являются характерные конструктивно-пластические формы в художественной керамики данной эпохи. Благодаря современным археологическим раскопкам и этнографическим исследованиям были обнаружены довольно многочисленные керамические изделия древней Гянджи раннего железного века. Научное исследование керамических изделий гончарного ремесла древней Гянджи XII-VII веков до нашей эры (эпохи раннего железа) с этнографической точки зрения способствует открытию новых весомых фактов, а также выявлению новых декоративно-орнаментальных особенностей художественной керамики.

\section{References:}

1. P.M. Taylor, Jasper W-Q., W.B. Smith. Turkmenistan: Ancient Arts Today. Asian Cultural History Program. Smithsonian Institution. 2011

2. Акунова Л.Ф., Приблуда С.З. Материаловедение и технология производства художественных керамических изделий. М.: Высшая школа, 1979, 216 с.

3. The dawn of Art. Leningrad: Aurora Art Publishers, 1974, 196 p.

4. Dyson R. Early Cultures of Solduz, Azerbaijan// A Survey of Persian Art. London, 1967, v.14, p. 301-440

5. Həsənov E.L. Azərbaycan ziyarətgahları: Gəncə İmamzadə türbəsi (tarixi - etnoqrafik tədqiqat). Bakı: Elm və təhsil, 2012, $268 \mathrm{~s}$.

6. Мусеибли Н.А. Археологические раскопки в Земямчайском некрополе // Археология и этнография Азербайджана. Баку, 2004, №2

7. Guliyeva N.M., Hasanov E.L. Investigation of basic decorative-applied arts of Ganja on the basis of some innovative arguments and technologies / Science and Society: Proceedings of the 3rd International scientific-practical conference. London: SCIEURO, London, (Great Britain), 2013, p. 281-291

8. Stein A. An Archaeological Tour in Gedrosia // Memoirs of the Archaeological Survey of India. Calcutta, 1931,№ 43, p. 306

9. Häsänov E.L. Die Gändschänischen teppiche von XIX - XX Jahrhundert als geschichtliche - ethnographische quelle / European Science and Technology (Die Europäische Wissenschaft und die Technologien): $2^{\text {nd }}$ International scientific conference. Bildungszentrum Rdk e. V. Wiesbaden, 2012, p. 26-27

10. Sulimirski T. Scythian Antiquities in Western Asia // Artibus Asiae. Ascona, 1954, v.17, № 3-4

11. Гасанов Э.Л. Историко-этнографическая характеристика художественной керамики древней Гянджи // Международный научный журнал Интеллект, Тбилиси, 2010 №3 (38), с.72-75

12. Sams G. K. Phrigian painted Animals: Anatolian orientalizing Art // Anatolian Studies. London, 1974, v.24

13. Hasanov E.L. Some innovation historic-ethnographical arguments about development of craftsmanship in Ganja / Science, Technology and Higher education: Proceedings of the 1st International scientific - practical conference. Westwood: Publishing office Accent Graphics communications, 2012, p. 485-491

14. Ergenekon Cavidan. Tempe keçe sanatında geleneksel süsleme üsulları ve günümüzde bu saneye yönelik yeni yaklaşımlar / Azərbaycan xalçası və xalq tətbiqi sənəti mövzusunda III Beynəlxalq simpoziumun materialları. Bakı: Elm, 2005, s. 45-46 